\title{
C3 degradation products (C3d) in normal pregnancy
}

\author{
J S JENKINS, R J POWELL \\ From the Department of Immunology, University Hospital, Nottingham
}

SUMMARY Plasma C3 degradation products (C3d) were measured in 65 normal pregnancies and compared with those of non-pregnant women. No significant difference was detected between the two groups, although a difference had been previously reported. Plasma C3d estimations give an indication of complement activation and may be used as an indicator of disease activity in patients with systemic lupus erythematosus (SLE), irrespective of pregnancy.

Systemic lupus erythematosus (SLE) predominantly affects women of child bearing age and is a classical immune complex disease in which hypocomplementaemia is a feature, but the hypocomplementaemia reflects not only complement activation but also hypoproduction. ${ }^{1}$ Quantification of $\mathrm{C} 3 \mathrm{~d}$, a product of $\mathrm{C} 3$ activation, by the alternative or classical complement pathways, gives an indirect measurement of complement activation. The concentration of C3d can be used as an indicator of lupus activity. ${ }^{23}$ The role of $\mathrm{C} 3 \mathrm{~d}$ estimations in the management of pregnant women with SLE was questioned by a report, which stated that pregnancy itself could increase complement turnover, thus producing high $\mathrm{C} 3 \mathrm{~d}$ concentrations. ${ }^{4}$ We therefore measured the concentrations in a group of pregnant women.

\section{Material and methods}

Sixty five women at various stages of pregnancy were randomly requested to give an extra sample of blood during routine venepuncturing at an antenatal clinic. Women with pregnancy complications or who were receiving drugs were not excluded. The edetic acid plasma was separated within six hours of venepuncture and stored at $-186^{\circ} \mathrm{C}$ in a vapour phase liquid nitrogen container. A control group comprised 21 non-pregnant women and 18 men (age range 18 to 83 years).

C $3 \mathrm{~d}$ concentrations were measured using the double decker rocket immunoelectrophoresis method of Brandslund et al. ${ }^{5}$ Essentially, electrophoresis of $4 \mu \mathrm{l}$ edetic acid plasma was performed overnight $(2 \cdot 5$ $\mathrm{V} / \mathrm{cm}$ ) initially through a gel layer containing antihuman $\mathrm{C} 3 \mathrm{c}$ (Dako) and then through a layer containing antihuman $\mathrm{C} 3 \mathrm{~d}$ (Dako) where the $\mathrm{C} 3 \mathrm{~d}$ rockets

Accepted for publication 28 May 1987 were formed. After drying and staining the rocket heights of test samples and standards were measured and the $\mathrm{C} 3 \mathrm{~d}$ values calculated from a standard curve. The C3d concentration of the standard (normal serum incubated at $37^{\circ} \mathrm{C}$ for four days) was assigned an arbitrary value of 100 units $/ \mathrm{ml}$.

\section{Results}

Plasma C3d concentrations in the pregnant women were mean 8.2 (SD 2.3) units $/ \mathrm{ml}$. These values did not differ significantly from those found in controls $(8.6$ (2.3) units $/ \mathrm{ml}$ ) when the data were analysed using Student's $t$ test $(t=0.86,0.3<\mathrm{p}<0.4)$. The C3d concentration exceeded normal limits as defined by

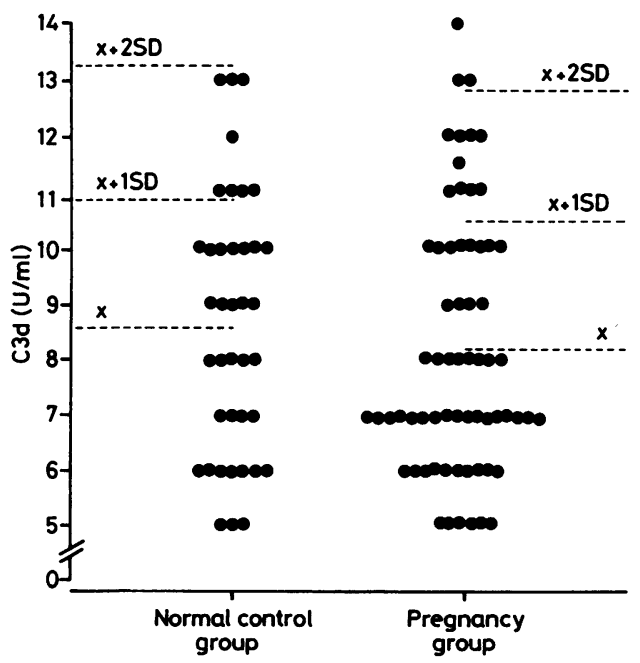

Fig 1 C3d concentrations in a) 39 normal controls and $b) 65$ pregnant women. 
the mean (SD) range in only one (1.5\%) sample from a pregnant woman (fig 1). Fig 2 shows C3d concentrations in relation to the duration of pregnancy.

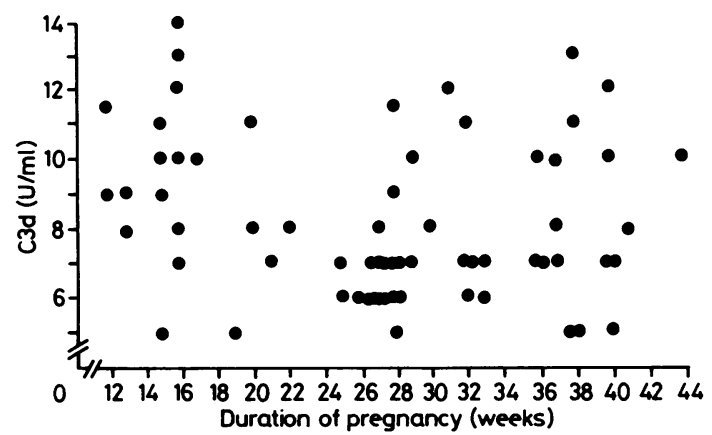

Fig 2 Plasma C3d concentration related to duration of pregnancy.

\section{Discussion}

Detectable amounts of $\mathrm{C} 3 \mathrm{~d}$ were present in all of the normal controls as well as in the pregnant women. This is not surprising because a "priming" C3 convertase is slowly assembled, continuously producing small amounts of C3 breakdown products. ${ }^{6}$ Our results indicate that the plasma $\mathrm{C} 3 \mathrm{~d}$ concentration is not significantly increased in pregnancy. Our findings do not agree with those of Teisner et al, ${ }^{4}$ who reported significant increases of $\mathrm{C} 3 \mathrm{~d}$ in the second and third trimesters when compared with nonpregnant women, those in the puerperium, or those in the first trimester of pregnancy. Furthermore, our study shows similar C3d concentrations in all three trimesters. We conclude that the value of $\mathrm{C} 3 \mathrm{~d}$ measurements is unaffected by uncomplicated pregnancy and can be used to monitor complement activation in systemic lupus erythematosus irrespective of pregnancy.

We thank Ms N Richards for her technical assistance and Mrs E Hall for her secretarial help.

\section{References}

1 Sliwinski AJ. Zvaifler NJ. Decreased synthesis of the third component of complement (C3) in hypocomplementaemic SLE. Clin Exp Immunol 1972;11:21-9.

2 Sturfelt G, Sjoholm A. Complement components, complement activation, and acute phase response in systemic lupus erythematosus. Int Archs Allergy Appl Immunol 1984;75:75-83.

3 Perrin LH, Lambert PH, Miescher PA. Complement breakdown products in plasma from patients with systemic lupus erythematosus and patients with membranoproliferative or other glomerulonephritis. J Clin Invest 1975;56:165-76.

4 Teisner B, Hau J, Tucker M, Lahood J, Grudzinskas J. Circulating C3, C4 and C3 split products (C3c and C3d) during normal pregnancy. Am J Rep Immunol 1982;2:309-11.

5 Brandslund J, Siersted HC, Svehag S, Teisner B. Double-decker rocket immunoelectrophoresis for direct quantitation of complement C3 split products with C3d specificities in plasma. J Immunol Methods 1981;44:63-71.

6 Fearon DI. Austen KF. Current concepts in immunology the alternative pathway of complement. A system for host resistance to microbial infection. $N$ Engl J Med 1980;303:259-63.

Requests for reprints to: $\operatorname{Dr} \mathbf{R}$ J Powell, Consultant Immunologist, University Hospital, Queen's Medical Centre, Nottingham NG7 2UH, England. 